CASE REPORT

\title{
Retention of dopamine 2 receptor mRNA and absence of the protein in craniospinal and extracranial metastasis of a malignant prolactinoma: a case report
}

J Winkelmann, U Pagotto ${ }^{1}, \mathrm{M}_{\text {Theodoropoulou }}{ }^{1}, \mathrm{~K}_{\text {Tatsch }}{ }^{3}$, W Saeger ${ }^{5}$, A Müller $^{4}$, T Arzberger ${ }^{1}$, L Schaaf ${ }^{1}$, E M Schumann ${ }^{2}$, C Trenkwalder and GK Stalla ${ }^{1}$

Departments of Neurology, ${ }^{1}$ Neuroendocrinology, and ${ }^{2}$ Magnetic Resonance Imaging, Max-Planck-Institute of Psychiatry, Munich, Germany, Departments of ${ }^{3}$ Nuclear Medicine and ${ }^{4}$ Neurosurgery, Klinikum Grosshadern, Ludwig Maximilians University of Munich, Germany and

${ }^{5}$ Department of Pathology, Marienkrankenhaus, Hamburg, Germany

(Correspondence should be addressed to Juliane Winkelmann, Max Planck Institute of Psychiatry, Neurology, Kraepelinstr. 10, 80804 Munich, Germany; Email: janew@mpipsykl.mpg.de)

(J Winkelmann and U Pagotto contributed equally to this work)

\begin{abstract}
Objectives: The case presented here describes the clinical evolution of a malignant prolactinoma with occurrence of intra- and extra-cranial metastases. In this case, the presence of dopamine 2 receptor (D2R) was studied at the mRNA and protein level, in order to understand the pathological background of the resistance to treatment with different dopamine agonists.

Design: Together with an extensive description of the clinical history of this case, a combination of in vitro and in vivo techniques was performed to provide the basis of the dopamine resistance developed in the course of the disease.

Method: A comparison of the D2R was performed in specimens obtained at presentation of the disease compared with autoptic specimens derived from local invasion and metastasis using in situ hybridization and immunohistochemical techniques.

Results: Intact D2R mRNA was found in the primitive tumor and metastatic tissues, whereas protein for the same receptor was present only in the tissues derived from neurosurgical operations and not in the metastases obtained post-mortem.

Conclusion: This is the first report of the absence of D2R protein despite the retention of the transcript in an advanced stage of a malignant prolactinoma. The findings of this single case suggest the hypothesis that postranscriptional mechanisms may contribute to the development of dopamine resistance in prolactinomas.
\end{abstract}

European Journal of Endocrinology 146 81-88

\section{Introduction}

Pituitary carcinomas are extremely rare neoplasms which are distinguishable from invasive pituitary adenomas by the presence of systemic and/or cerebrospinal metastases. The rarity of such neoplasms is highlighted in a recent review, in which 64 cases are described after summarizing all the relevant literature. Of these, $74 \%$ were hormone producing and the remaining $26 \%$ were considered endocrinologically non-functioning (1). The subgroup occurring with the highest frequency is the prolactin (PRL)-producing carcinomas. Here, we report a case of PRL-producing carcinoma, which showed both cerebrospinal and systemic metastases despite repetitive surgical intervention, pharmacological therapy and stereotactic radiotherapy. In this particular case, usage of different dopamine agonists, even at high dosages, has been unable to prevent the malignant growth of the tumor. This is in line with previous reports demonstrating that resistance to dopamine agonist drugs often leads to invasive behavior (2). To investigate the mechanism of the in vivo resistance to dopamine, we examined the dopamine 2 receptor (D2R) status at the mRNA and protein level in tissues derived from successive surgical operations and from autopsy.

\section{Case report}

A 53-year-old male presented in 1991 with progressive loss of vision and constant headache. Physical examination revealed bitemporal hemianopia, and a cranial computed tomographic scan (CT scan) showed a contrast-enhancing pituitary tumor with suprasellar extension $(2 \times 3 \mathrm{~cm})$. Endocrinological evaluation revealed elevated serum PRL levels $(318 \mathrm{ng} / \mathrm{ml}$; normal 
$<25 \mathrm{ng} / \mathrm{ml}$ ), decreased luteinizing hormone (LH) $(0.5 \mathrm{mU} / \mathrm{ml}$; normal $0.5-10 \mathrm{mU} / \mathrm{ml})$, follicle-stimulating (FSH) $(2.9 \mathrm{mU} / \mathrm{ml}$; normal $0.8-9.0 \mathrm{mU} / \mathrm{ml})$ and testosterone $(<2.0 \mathrm{nmol} / \mathrm{l}$; normal $7.0-29.5 \mathrm{nmol} / \mathrm{l})$ levels, while adrenocorticotropin (ACTH) and thyrotropin (TSH) values were normal. Treatment with up to $15 \mathrm{mg} /$ day bromocriptine (BRC) led to a decline in PRL levels to normal values, accompanied by an improvement of the visual field defect and a considerable shrinkage of tumor size as demonstrated by magnetic resonance imaging (MRI).

Follow-up examinations at the end of 1994 revealed a worsening of the visual field defect. A new MRI scan showed a recurrence of the tumor with marked suprasellar extension, together with a lateral displacement of the left internal carotid artery. Neither the increase of BRC dosage to $60 \mathrm{mg}$ /day, nor the administration of the more potent dopamine agonist (DA), quinagolide, up to $300 \mu \mathrm{g} /$ day, succeeded in inducing tumor shrinkage and reducing the high PRL levels $(4360 \mathrm{ng} / \mathrm{ml}$ ); surgery was therefore performed. Two operations were needed; the first used a transphenoidal route and the second used a transfrontal approach, because of the remaining tumor mass. After the first operation the patient decided to discontinue medical treatment. When the pharmacological treatment started again, it was accompanied by irradiation therapy, with an overall dosage of $54 \mathrm{~Gy}$. PRL levels initially fell $(385 \mathrm{ng} / \mathrm{ml})$ but increased again 6 months later while the patient was still under treatment with quinagolide (150 $\mu \mathrm{g} /$ day). For this reason higher doses of this drug were progressively administered (up to $600 \mu \mathrm{g}$ /day). Moreover, in this period substitution hormonal therapy with testosterone, levothyroxine and hydrocortisone was initiated. In 1997, a further increase of PRL levels (from $894 \mathrm{ng} / \mathrm{ml}$ to 9586 $\mathrm{ng} / \mathrm{ml}$ ) indicated that treatment with a maximal dosage of quinagolide $(900 \mu \mathrm{g} /$ day $)$ should be started. In the same period, MRI examination revealed a massive expansion of the tumor extending into the cavernous sinus and the left orbit with a protrusion of the left eye (Fig. 1A). At this point, the first D2R ${ }^{123}$ I-methoxybenzamide single photon emission tomography $\left({ }^{123}\right.$ I-IBZM SPECT) showed no proof of specific IBZM binding in the projection of the hypophyseal area. Specific IBZM binding to the post-synaptic D2R of the striatum on both sides showed lower values $(0.47)$ compared with normal age-matched controls (controls:
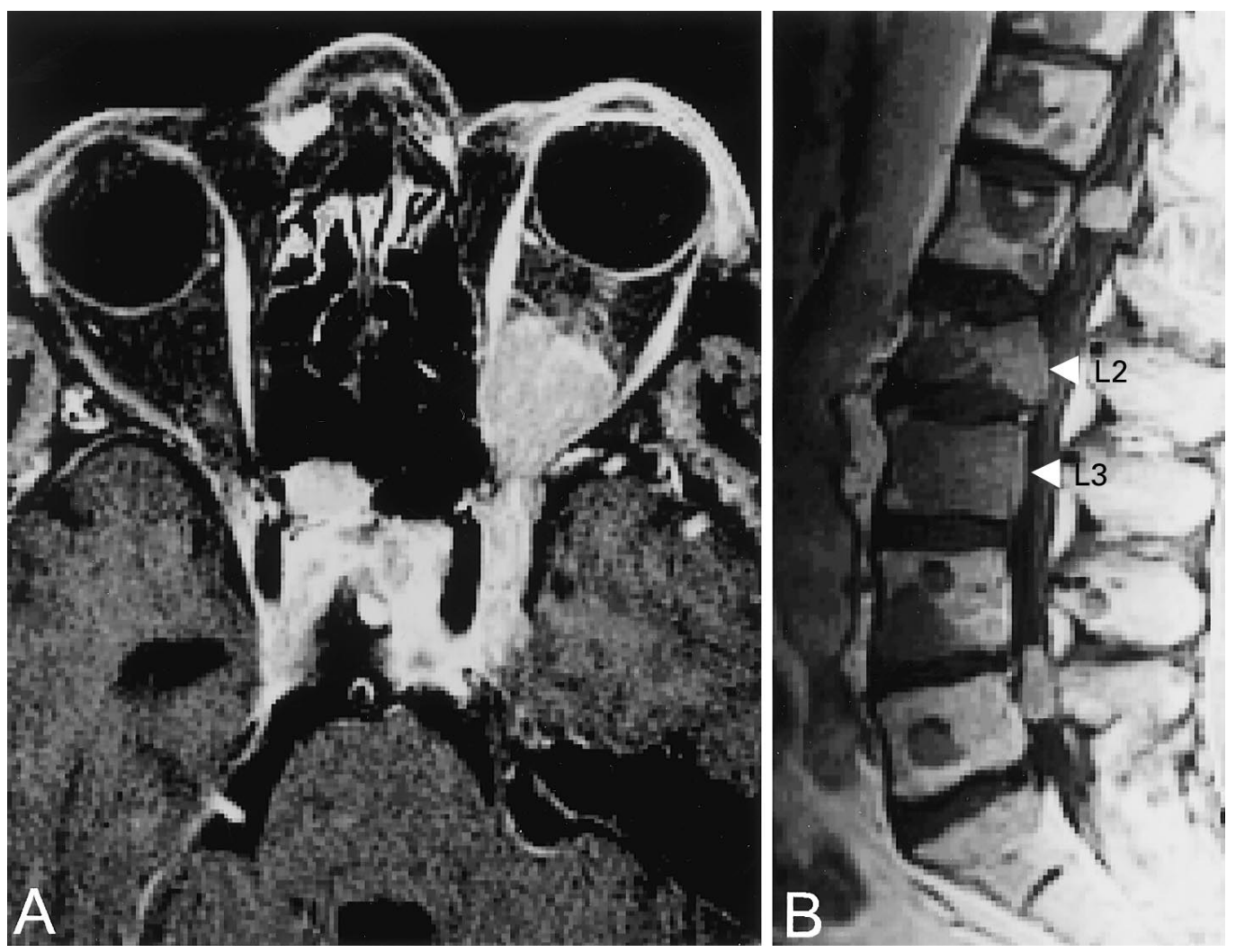

Figure 1 (A) Axial contrast-enhanced T1-weighted image with fat suppression, demonstrating residual invasive tumor extending into the orbit with anterior displacement of the globe, indicating aggressive growth. (B) Sagittal contrast-enhanced T1-weighted image reveals two well defined enhancing spinal lesions in the lumbar region and multiple foci of low signal-intensity material with varying degrees of enhancement in the vertebral bodies, replacing the high intensity fatty marrow, consistent with metastatic disease. Note epidural tumor expansion in L3 and thecal sac compression from L2 fracture. 
$0.65 \pm 0.05)$. The slightly reduced IBZM binding to the striatal areas in comparison with normal controls was probably caused by dopaminergic treatment $(900 \mu \mathrm{g}$ quinagolide/day up to 2 days prior to the SPECT study). A new treatment with cabergoline (CAB) ( $2 \mathrm{mg}$ /day) was initiated and stereotactic radiosurgery $(\gamma$-knife) treatment was performed leading to an initial reduction of the tumor mass. However, the PRL levels were constantly increasing, and a second stereotactic radiosurgery ( $\gamma$-knife) treatment was initiated. Early in 1998, the patient reported back pain, weakness of the right leg and loss of the right ankle reflex. Serum PRL levels were much higher than previously observed $(>100000 \mathrm{ng} / \mathrm{ml})$. MRI examination showed an extramedullary tumor mass compressing the cervical medullary junction at the level of the foramen magnum, and masses at the level of the medulla oblongata, spinal cord, thoracic and lumbar vertebral bodies (Fig. 1B). A second D2R ${ }^{123}$ I-IBZM SPECT was performed (1998) revealing no specific tracer uptake in the masses. Again, IBZM binding to the D2R of the striatum showed slightly lower values (0.49) compared with controls because of dopaminergic treatment $(600 \mu \mathrm{g}$ cabergoline up to 4 days prior the SPECT study). Finally, the patient had shortness of breath followed by renal failure and subsequently died of lung edema 5 weeks after detection of the extrapituitary masses. The clinical history and course of treatment of the patient from 1994 is summarized in Fig. 2.

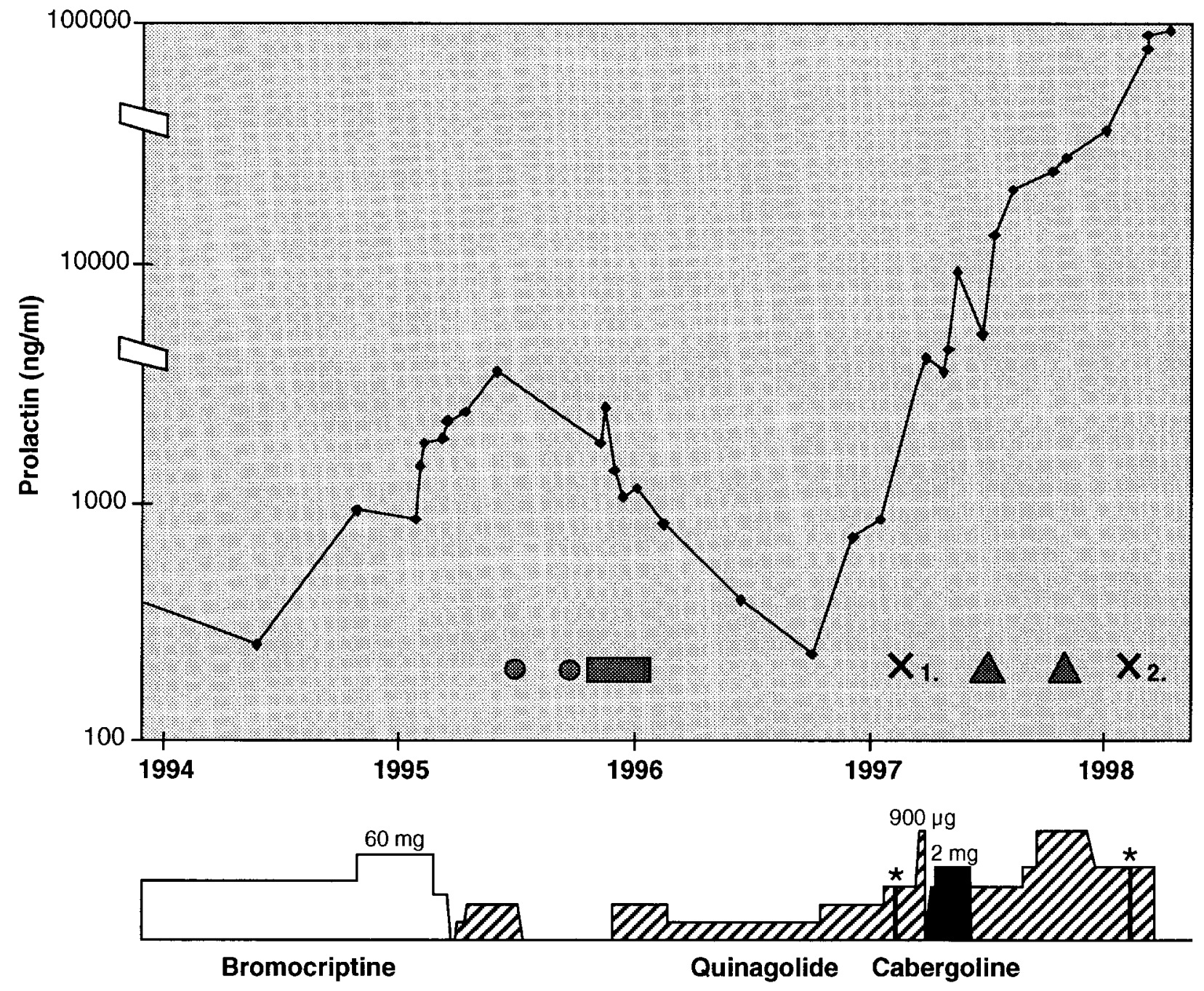

Figure 2 Serum PRL levels during the course of treatment. In the bottom panel pharmacological treatments with bromocriptine (open area), quinagolide (hatched area) and cabergoline (solid area) are shown. The asterisk indicates temporary interruption of the treatment because of the requirements of SPECT analysis. In the top panel, the shaded circle $=$ neurosurgical operation, shaded box $=$ radiotherapy, shaded triangle $=\gamma-$ knife therapy, $\mathrm{X} 1 .=1$ st $^{123} \mathrm{I}-\mathrm{IBZM}-\mathrm{SPECT}, \mathrm{X} 2 .=2 \mathrm{nd}^{123} \mathrm{I}-\mathrm{IBZM}-\mathrm{SPECT}$. 


\section{Materials and methods}

\section{Tissues}

All tissue specimens from the 1st and 2nd operations, and post-autoptic specimens derived from parasellar and orbital invasion, and from metastases derived from medulla oblongata, spinal canal and left femur were collected and processed for routine histological examination (hematoxylin-eosin and periodic acidSchiff). A portion of each specimen was snap-frozen for in situ hybridization (ISH) and immunohistochemistry (IHC). Two normal human pituitary glands (taken 8-12 h after demise from autopsy cases after sudden
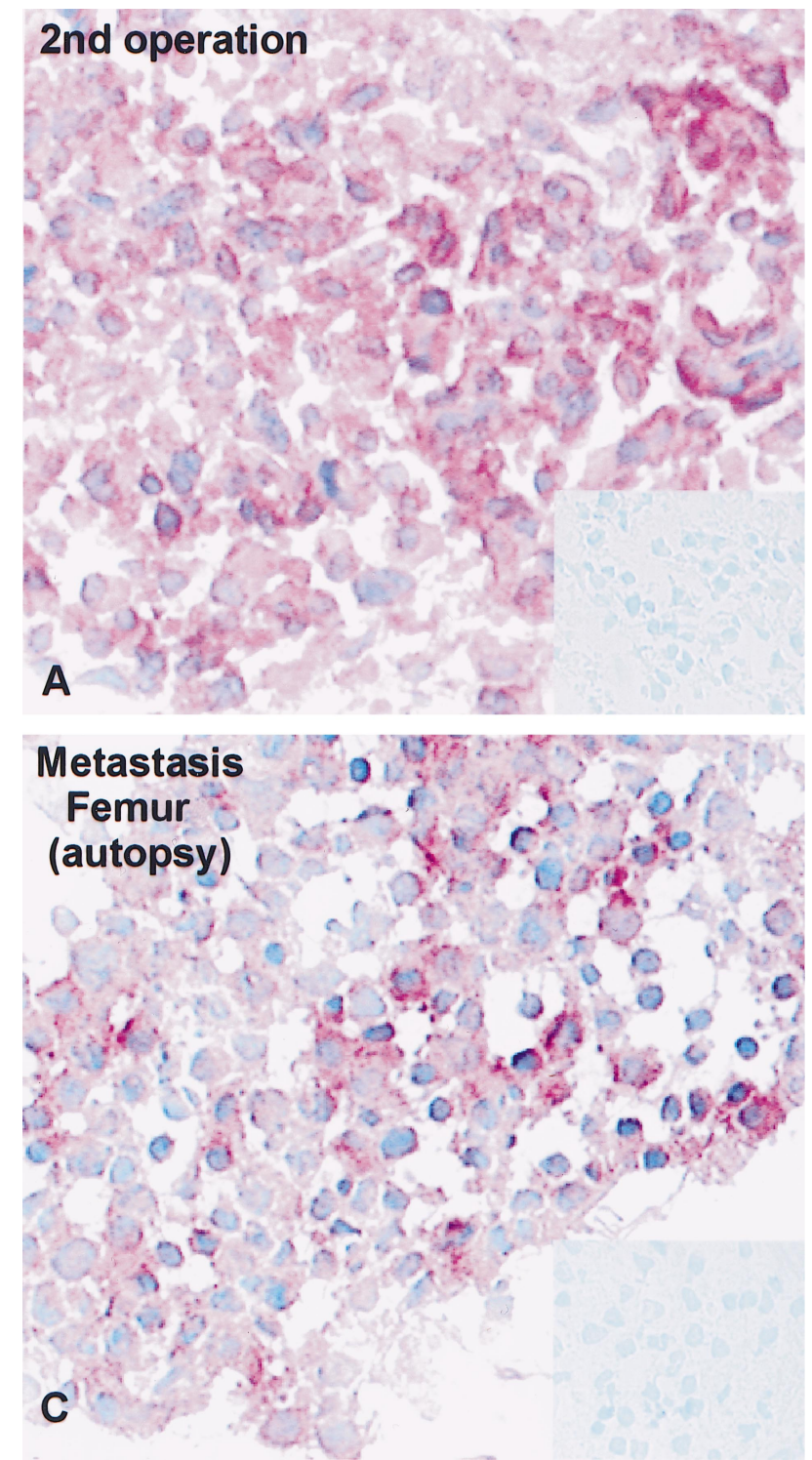

death without any evidence of endocrine disease) were included in the study as positive controls.

\section{In situ hybridization}

ISH for D2R was performed as previously described (3). In brief, $8-\mu \mathrm{m}$ sections were thaw-mounted onto sterile poly-L-lysine-coated slides, fixed in $4 \%$ phosphatebuffered paraformaldehyde and stored in $96 \%$ ethanol at $4{ }^{\circ} \mathrm{C}$ until use. Oligodeoxynucleotides (ODN; MWG Biotech, Ebersberg, Germany) against the long (D2;; position 724-765) and the short (D2s; position 704743) D2R subtypes and against a common domain
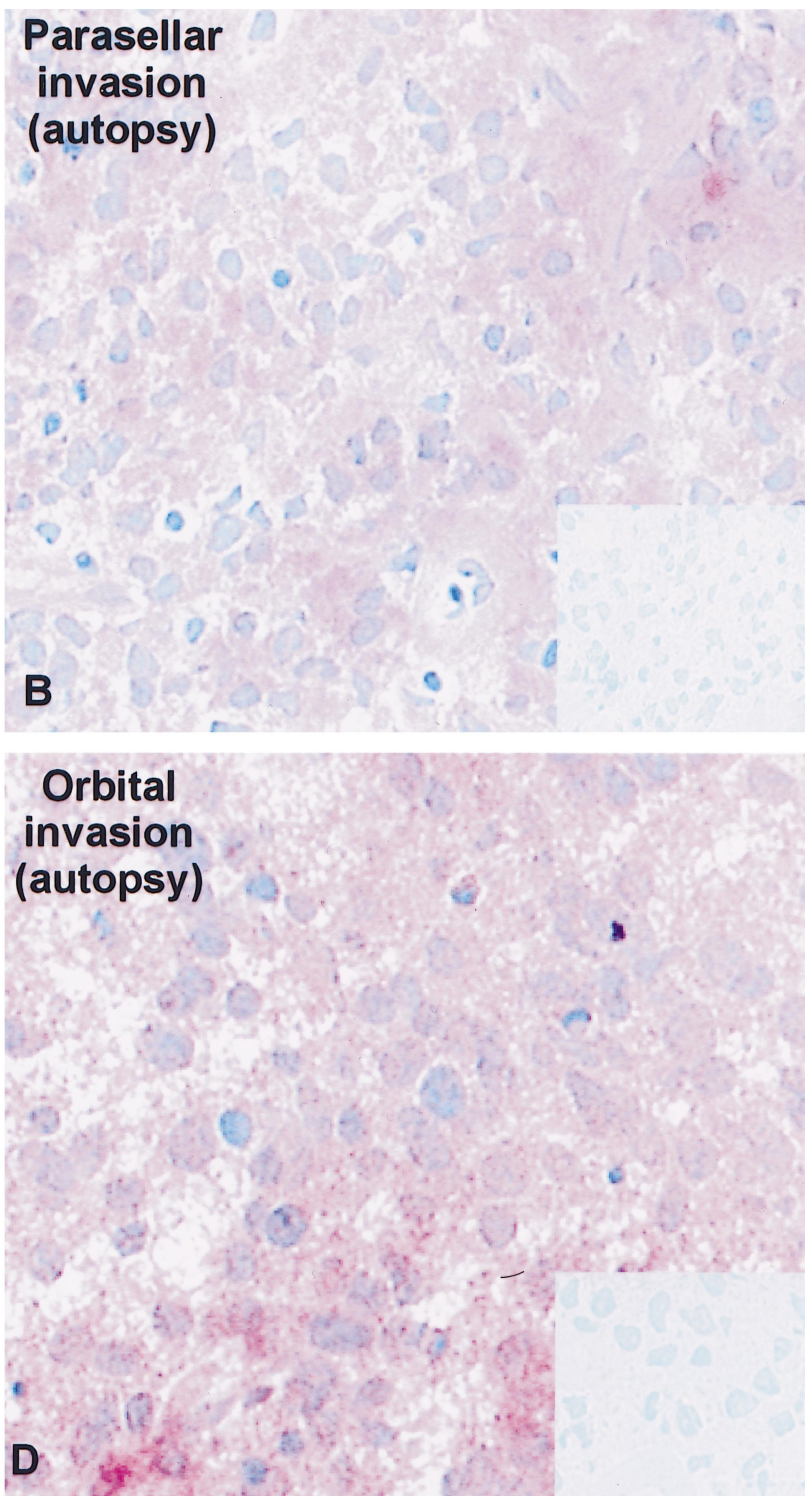

Figure 3 Immunohistochemical staining for prolactin in the tumoral pituitary specimens derived from (A) the second transfrontal operation (2nd operation) and autoptic samples from (B) parasellar invasion, (C) femur metastasis and (D) orbital invasion. PRL immunoreactivity is shown by the red color. The small insets show negative controls in the absence of primary antibody. Nuclei are counterstained with toluidine blue. 
ISH
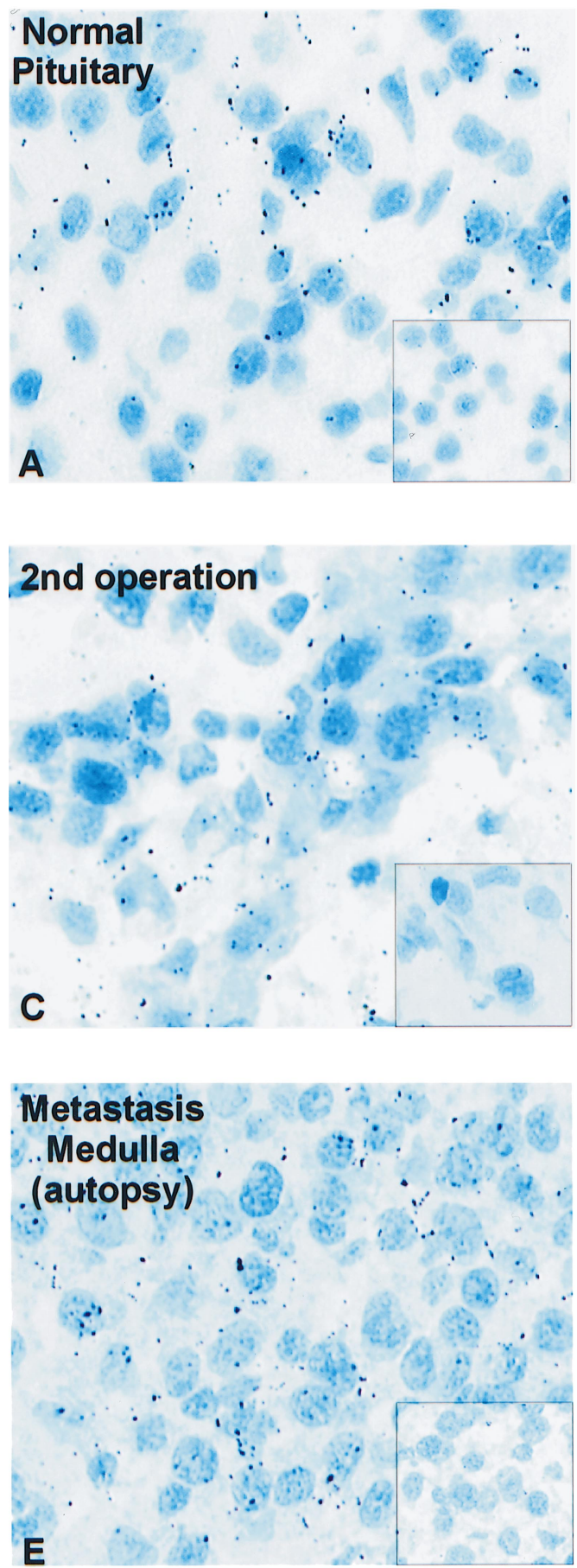

IHC
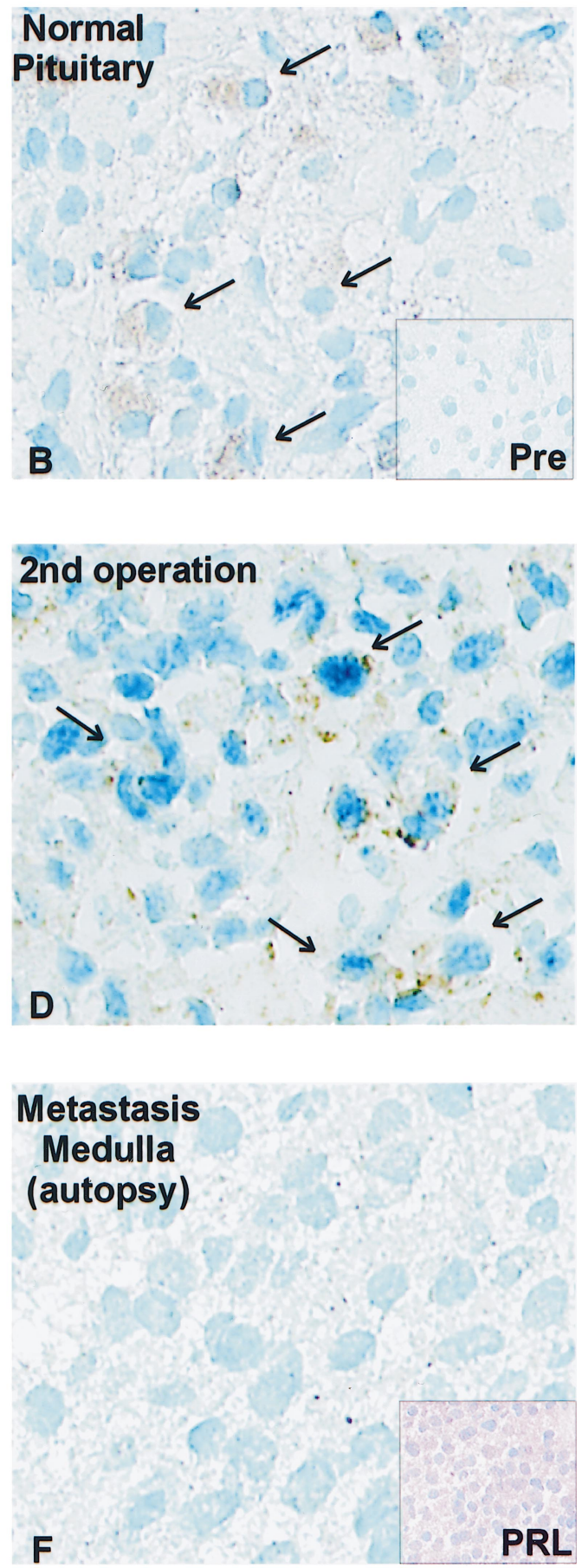

Figure 4 Expression of D2R mRNA and protein in normal human pituitary and in tumoral samples derived from the second transfrontal operation (2nd operation) and from the medulla oblongata metastasis obtained by autopsy. (A) Histoautoradiograph of D2R mRNA (ISH) in normal human pituitary cells of the anterior lobe. Small inset: negative control was performed after incubating the adjacent section with 100-fold excess of unlabeled probe. (B) Cytoplasmic immunoreactivity (IHC) for D2R protein (brown color) is detectable in many cells of the normal human anterior pituitary (arrows). Small inset: signal specificity as demonstrated using pre-absorbed serum (Pre). (C) Histoautoradiograph of D2R mRNA (ISH) in a specimen derived from the second operation reveals many silver grains in the tumoral cells. Small inset: negative control performed with 100-fold excess of unlabeled probe. (D) D2R protein immunoreactivity (brown color) in tumoral cells from the second operation (arrows). (E) ISH for D2R in a metastasis localized in the medulla oblongata. Note the presence of silver grains, indicative of the retention of D2R mRNA. Small inset: negative control in the presence of 100-fold excess of unlabeled probe. (F) Absence of D2R protein in an adjacent section of the metastatic specimen derived from the medulla oblongata. Small inset: PRL immunoreactivity, as shown by the red color, confirms the ability of the metastasis to produce PRL. Nuclei are counterstained with toluidine blue. 
(D2 $2_{\text {total }}$; position 1022-1063) of the two splice variants were designed as previously described (3), and were 3 'end labeled with $\left[\alpha-{ }^{33} \mathrm{P}\right] \mathrm{dATP}$ (NEN Life Science Inc., Boston, MA, USA) by terminal transferase (Roche Molecular Diagnostics, Mannheim, Germany). After hybridization and washing, sections were dipped in Ilford K5 photoemulsion (Ilford, Dreieich, Germany) and developed after 28 days. For negative control, a 100-fold excess of nonlabeled ODN was added to the radioactive probe and applied to the adjacent section on the same slide.

\section{Immunohistochemistry}

Primary antibodies $(\mathrm{Ab})$ and dilutions were: mouse monoclonal anti-human $\beta$-FSH (1:500), anti-human $\beta$-LH (1:500), anti-human $\beta$-TSH (1:800), antihuman PRL (1:400), anti-human $\alpha$-subunit $(\alpha$-sub) (1:500) (all Immunotech, Karlsruhe, Germany), antihuman ACTH (1:100), (Dako Diagnostika, Hamburg, Germany), anti-human growth hormone (GH) (1:800; a gift from Dr CJ Strasburger, Dept. of Medicine, Ludwig-Maximilian University, Munich, Germany), anti-S-100 (1:20) (Biogenesis Ltd, Poole, Dorset, UK), and MIB-1 (1:100; Dako Diagnostika). IHC for D2R was performed using a polyclonal goat $\mathrm{Ab}$ against the common domain at the amino terminus of the receptor (sc-7522, SantaCruz Biotech, Santa Cruz, CA, USA).

IHC was performed as previously described (4). In brief, slides were incubated for $30 \mathrm{~min}$ in horse serum (1:10; Sigma, Deisenhofen, Germany) in Tris-based buffer (TBS) and with the primary antibody, overnight at $4{ }^{\circ} \mathrm{C}$. After washing in TBS, sections were incubated for $30 \mathrm{~min}$ in horse anti-mouse biotinylated antibody for the hormones and MIB or horse anti-goat biotinylated antibody for the D2R (both 1:300; Vector Laboratories, Burlingame, CA, USA) and in biotin-alkaline phosphatase complex (ABC-AP; Vector Laboratories) for the pituitary hormones or biotin-peroxidase (ABC; Vector Laboratories) for the MIB-1 and D2R for $30 \mathrm{~min}$. Immunoreactivity was visualized using the Vector Red reaction kit (Vector Laboratories), supplemented with levamisole (10 mmol/l; Sigma), when ABC-AP was applied, or $1 \mathrm{mg} / \mathrm{ml}$ diaminobenzidine (DAB; Sigma) with $0.01 \%$ hydrogen peroxide when ABC was used. After washing in water, the sections were counterstained with toluidin blue, fixed in xylol and coverslipped using Entellan (Merck, Darmstadt, Germany).

Controls were performed by omitting the primary Ab. In addition, for D2R immunostaining a further control was provided after preabsorption of the $A b$ with the antigenic peptide (Santa Cruz Biotech).

\section{Results}

\section{Molecular pathology}

The specimens derived from the first two operations were composed of monomorphic cells. Nuclei were pleomorphic and contained small nucleoli. Some cells had double nuclei. No mitotic figures were observed. Cytoplasm was weakly basophilic. Staining with periodic acid-Schiff was negative. Signs of necrosis (shrinkage and condensed nuclei) were observed in $10 \%$ of the cells, and some areas of fibrosis were present. Twenty percent of the cells were positive after staining with the proliferation marker MIB-1 (5) (data not shown). The post-autoptic primary localizations (parasellar and orbital) and the metastases showed monomorphic cells of medium size, with moderately pleomorphic nuclei showing a lost pattern of chromatin. Some calcifications of psammoma body-type and siderin-containing macrophages were found. Ten percent of the cells were MIB-1 positive (data not shown).

IHC revealed variable levels of immunoreactivity only for PRL in all tissue samples (examples from tumor derived from the 2 nd operation, and from parasellar and orbital invasion, femur and medulla oblongata metastases specimens are given in Fig. 3A-D and Fig. 4F inset), whereas all other pituitary hormones and $\alpha$-subunit were immunonegative (data not shown).

\section{D2R expression}

ISH for D2R revealed an abundance of D 2 total hybridization signals in post-operative (Fig. 4C) and autoptic (Fig. 4E) tissues, comparable to the signals obtained from the lactotroph-rich region of the normal pituitaries (Fig. 4A). In all specimens, D2 1 mRNA was the subtype predominantly expressed, whereas the $\mathrm{D} 2_{\mathrm{s}}$ mRNA was expressed at low levels, similar to the normal pituitary (data not shown). When immunohistochemically assessed, all the post-operative specimens and the normal pituitaries revealed an intense immunoreactivity for D2R (Fig. 4B and 4D). However, the autoptic samples derived from invasion and metastasis were immunonegative for the receptor (example: medulla oblongata in Fig. 4F), indicating a loss of D2R protein in these tissues.

\section{Discussion}

Prolactinomas are usually benign pituitary tumors which have an excellent prognosis with DA treatment. Although these neoplasms often grow invasively inside the sella turcica, occurrence of real malignancy is extremely rare (2). Histological diagnostic criteria for malignancy are not clear because cellular pleomorphism is rare in pituitary tumors and seems not to correlate with the occurrence of metastasis (6). Therefore malignancy is defined by (a) a definite histological identification of the pituitary tumor, (b) a metastasis showing discontinued growth with regard to the primary tumor, (c) structures of the metastasis similar to those of the primary hypophyseal tumor, and (d) not corresponding to any other primary tumor (6). The definite 
confirmation of malignancy is usually a post mortem diagnosis.

Herein we describe a case of a malignant prolactinoma with extra-axial intracranial and intraspinal as well as extracerebral metastases. In all the tumoral tissues, $10-20 \%$ of cells were found to express MIB-1, which is in line with previous publications which have found high MIB-1 values in pituitary carcinoma cases $(1,7)$.

In a review of 15 cases of malignant prolactinomas, cerebrospinal (intracranial) metastases were described mainly in the cerebellum, cerebellopontine angle, frontal lobe, occipital region or spinal cord, whereas systemic (extracranial) metastases were documented in the liver, lung or bone (8). In the case presented here, spinal leptomeningial drop metastases were documented at the level of the medulla oblongata and the thoracal and lumbar region, as well as metastases of the thoracal and lumbar vertebra and the left femural bone. The metastases were morphologically recognized to be of hypophyseal origin and immunohistochemically identified after PRL positive staining.

After an initial period of response to BRC treatment, the prolactinoma became resistant first to BRC and later to the more potent DAs such as quinagolide and CAB. Resistance to BRC therapy is found in about 5\% of prolactinomas (2), but recently two selective D2R agonist compounds, quinagolide and $\mathrm{CAB}$, have been shown to treat successfully nearly half of these cases (9). Correlation has been demonstrated between DA response and visualization of the tumor by SPECT using the high affinity D2R radioligand ${ }^{123} \mathrm{I}$-IBZM (10). Two consecutive ${ }^{123}$ I-IBZM-SPECT investigations, performed when our patient was no longer responsive to DA treatment were not able to visualize the pituitary tumor or metastases. Therefore, our study is in line with previous findings proposing ${ }^{123} \mathrm{I}$-IBZM in vivo imaging as a potential means for predicting the inhibitory effect of DA on PRL secretion in pituitary tumors (11).

Caccavelli and coworkers have proposed that a concomitant reduction of D2R mRNA and dopamine binding may account for the development of DA resistance (12). In our study, no changes in the D2R gene expression were observed among the different specimens when compared with each other, and there was no obvious change in the $\mathrm{D} 2_{\mathrm{s}} / \mathrm{D} 2_{1}$ ratio in the tissues examined. A relevant finding of our investigation is that no D2R immunoreactivity was present in any autoptic tissues despite the fact that D2R mRNA was observed in adjacent slides from the same specimens. To our knowledge, this is the first evidence of absence of $\mathrm{D} 2 \mathrm{R}$ protein, as detected by IHC, in the presence of normal gene expression in a pituitary adenoma. This finding can explain a previous report of Kovacs et al. in which D2R mRNA was present in a rapidly growing and invasive PRL-producing tumor which failed to respond to DA medication (13). These findings indicate that in some cases of DA resistance, posttranscriptional defects can explain the failure of the medical therapy $(14,15)$. At present, there is no report providing an explanation for the absence of D2R protein in the presence of gene expression. Mechanisms such as ubiquitination and subsequent proteosomal degradation (16, 17) may be hypothesized to be responsible for $D 2 R$ protein down-regulation.

In summary, in this report we describe a malignant transformation of a PRL-secreting pituitary tumor, in which resistance to DA therapy was followed by aggressive growth and ability to metastasize. A novel finding of this study is the observation that the malignant phenotype is associated with absence of D2R protein, but not to a concomitant reduction in D2R gene expression. The findings of this case report allow us to suggest that posttranscriptional mechanisms may be involved in the development of dopamine resistance in prolactinomas.

\section{Acknowledgements}

The authors gratefully acknowledge Y Grübler for her skilful technical assistance, Dr H Backmund and Dr M Schulte-Steinberg for helpful discussions regarding the management of this patient, Dr B Wowra for performing stereotactic radiosurgery, and Dr M Paez Pereda for critical reading of the manuscript.

\section{References}

1 Pernicone PJ, Scheithauer BW, Sebo TJ, Kovacs KT, Horvath E, Young WF et al. Pituitary carcinoma: a clinicopathologic study of 15 cases. Cancer $1997 \mathbf{7 9} 804-812$.

2 Colao A \& Lombardi G. Growth hormone and prolactin excess. Lancet 1998352 1455-1461.

3 Renner U, Arzberger T, Pagotto U, Leimgruber S, Uhl E, Muller A et al. Heterogeneous dopamine D2 receptor subtype messenger ribonucleic acid expression in clinically nonfunctioning pituitary adenomas. Journal of Clinical Endocrinology and Metabolism 1998 83 1368-1375.

4 Pagotto U, Arzberger T, Theodoropoulou M, Grubler Y, Pantaloni $\mathrm{C}$, Saeger $\mathrm{W}$ et al. The expression of the antiproliferative gene ZAC is lost or highly reduced in nonfunctioning pituitary adenomas. Cancer Research $2000606794-6799$.

5 Lange M, Pagotto U, Hopfner U, Ehrenreich H, Oeckler R, Sinowatz $\mathrm{F}$ et al. Endothelin expression in normal human anterior pituitaries and pituitary adenomas. Journal of Clinical Endocrinology and Metabolism 1994 79 1864-1870.

6 Lubke D \& Saeger W. Carcinomas of the pituitary: definition and review of the literature. General and Diagnostic Pathology 1995 $14181-92$.

7 Thapar K, Kovacs K, Scheithauer BW, Stefaneanu L, Horvath E, Pernicone PJ et al. Proliferative activity and invasiveness among pituitary adenomas and carcinomas: an analysis using the MIB-1 antibody. Neurosurgery 199638 99-106.

8 Popadic A, Witzmann A, Buchfelder M, Eiter H \& Komminoth P. Malignant prolactinoma: case report and review of the literature. Surgical Neurology $19995147-54$.

9 Colao A, Di Sarno A, Marzullo P, Di Somma C, Cerbone G, Landi ML et al. New medical approaches in pituitary adenomas. Hormone Research 200053 (Suppl 3) 76-87.

10 de Herder WW, Reijs AE, Kwekkeboom DJ, Hofland LJ, Nobels FR, Oei HY et al. In vivo imaging of pituitary tumours using a radio- 
labelled dopamine D2 receptor radioligand. Clinical Endocrinology $199645755-767$

11 Ferone D, Lastoria S, Colao A, Varrella P, Cerbone G, Acampa W et al. Correlation of scintigraphic results using ${ }^{123} \mathrm{I}$-methoxybenzamide with hormone levels and tumor size response to quinagolide in patients with pituitary adenomas. Journal of Clinical Endocrinology and Metabolism $1998 \mathbf{8 3} 248-252$.

12 Caccavelli L, Feron F, Morange I, Rouer E, Benarous R, Dewailly D et al. Decreased expression of the two D2 dopamine receptor isoforms in bromocriptine-resistant prolactinomas. Neuroendocrinology $199460314-322$.

13 Kovacs K, Stefaneanu L, Horvath E, Buchfelder M, Fahlbusch R \& Becker W. Prolactin-producing pituitary tumor: resistance to dopamine agonist therapy. Case report. Journal of Neurosurgery $199582886-890$.

14 Pellegrini I, Rasolonjanahary R, Gunz G, Bertrand P, Delivet S, Jedynak CP et al. Resistance to bromocriptine in prolactinomas.
Journal of Clinical Endocrinology and Metabolism 198969 500-509.

15 Barlier A, Pellegrini-Bouiller I, Caccavelli L, Gunz G, MorangeRamos I, Jaquet P et al. Abnormal transduction mechanisms in pituitary adenomas. Hormone Research $199747227-234$.

16 Hicke L. Gettin' down with ubiquitin: turning off cell-surface receptors, transporters and channels. Trends in Cell Biology 1999 9 107-112.

17 Schwartz AL \& Ciechanover A. The ubiquitin-proteasome pathway and pathogenesis of human diseases. Annual Reviews in Medicine 199950 57-74.

Received 7 May 2001

Accepted 10 September 2001 